\section{Viloxazine: assessment of potential rapid antidepressant action}

Viloxazine (Vivalan) is a bicyclic compound with atypical pharmacological properties. ${ }^{1}$ Preliminary evidence suggested that it might have a rapid antidepressant effect." The following placebo-controlled trial was therefore carried out.

\section{Method and results}

The trial was undertaken in 34 moderately to severely depressed patients (nine inpatients, 25 outpatients), whose ages ranged from 18 to 64 . The criteria for inclusion and methods adopted have been described elsewhere. ${ }^{3}$ Patients were given either $100 \mathrm{mg}$ of viloxazine or identical placebo tablets three times a day for a week. Statistically significant differences at the $5{ }^{\circ}$ ". level or less will be reported unless otherwise specified.

Five patients did not adhere to treatment because of alleged unwanted effects. All of them were taking viloxazine. Of those who completed their treatment, 12 received viloxazine and 17 placebo. The age range for the viloxazine group was 18 to 61 (mean 39.5 ); that for the placebo group was 22 to 57 (mean 43.8). Five men and 12 women received viloxazine; seven men and 10 women received placebo. Of the viloxazine group, five were inpatients and 12 were outpatients; for placebo the figures were four and 13, respectively. Of the patients receiving viloxazine, five had been ill for less than three months, 10 for three months to two years, and two for longer than two years, the corresponding figures for placebo being five, six, and six, respectively.

Hamilton rating scale for depression-The mean total scores during the baseline were $24 \cdot 4$ and $20 \cdot 1$ for the viloxazine and placebo groups, respectively. The difference between these was not significant. The two populations therefore were matched for severity of depression on this scale. The mean scores following treatment were 23.7 and 14.4 respectively. The decrease in the score was significant $(P<0.01)$ for the placebo group, but not for the viloxazine group. The difference between the mean reduction in scores for the two groups was not significant. An analysis of the sum of the scores of the first three items on the Hamilton Scale, carried out for the purpose of comparison with reported results," showed a significant fall in the placebo group, but not in the viloxazine group

Wakefield self-assessment depression scale-The mean total scores during the baseline were 26.9 and $24 \cdot 2$ for the viloxazine and placebo groups, respectively. The difference between these was not significant. The two populations therefore were matched for severity of depression on this scale also. The mean scores after treatment were 27.2 and 18.4 respectively. The reduction in scores from before to after treatment with placebo was significant, and also significantly greater than the change that occured in the viloxazine group.

Global assessments-The differences in the global assessments of the severity of depression from before to after treatment, although showing a trend in favour of placebo, were not significant. The global assessments of change in condition shown in the table suggest that patients on placebo progressed better than those on viloxazine.

Unwanted effects-As expected when using a check-list, many symptoms identical to unwanted effects were elicited during the baseline and after treatment with placebo. It was therefore impossible to attribute any of the reported "side effects" to viloxazine with the possible exception of nausea and vomiting, which were more severe in the viloxazine group. There was no difference in the frequency of occurrence of drowsiness or anticholinergic effects. One patient receiving viloxazine had a grand mal seizure (BMF, 9 July, p 96). No relevant laboratory abnormalities were found.

\section{Conclusions}

These results suggest that viloxazine, $100 \mathrm{mg}$ given three times a day for a week, is not as effective as placebo. If this is a true and not a chance finding we have to consider the possibility of a "negative" effect, such as drug-induced, ill-defined feeling of dysphoria. In not showing advantages over placebo the findings also suggest that the results of those trials; that point towards viloxazine in a similar

Global assessment of change in condition

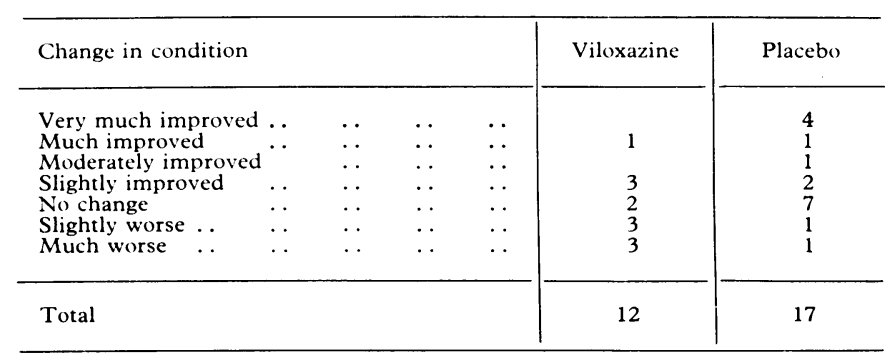

dosage having a rapid action-within one week-could be placebo responses.

I thank ICI Ltd, for providing the tablets for this trial; the pharmacy staff at Knowle Hospital; the pathology staff at Southampton University Hospitals and St Mary's Hospital, Portsmouth; Mr J A Lewis for his statistical and computer help; and Mrs Lynne Hitchins for her secretarial help.

${ }^{1}$ Mallion, K B, et al, Nature, 1972, 238, 157.

2 Bereen, F J, Lancet, 1973, 1, 379.

${ }^{3}$ Edwards, J G, and Ollerenshaw, D F, Current Medical Research and Opinion, 1974, 2, 305.

${ }^{4}$ Mahapatra, S B, fournal of International Medical Research, 1975, 3, Suppl No 3, 70 .

International Vivalan Symposium: fournal of International Medical Research, 1975, 3, Suppl No 3.

\section{(Accepted 12 fuly 1977)}

\section{Knowle Hospital, Fareham, Hants PO17 5NA}

J GUY EDWARDS, MB, FRCPSYCH, consultant psychiatrist

\section{A tumour inducing iron overload}

Ferritin may be isolated from normal tissues, hepatic metastases, and primary neoplastic tissues. ${ }^{1}$ We describe a patient with a primary bronchial carcinoma containing an abnormal ferritin that was thought to cause excess iron deposition in the liver and spleen.

\section{Case report}

A previously fit 72-year-old plumber gave a two-month history of anorexia, weight loss, and stabbing epigastric pain. He smoked 10 cigarettes and drank four pints of beer a day. He had a one-week course of iron tablets before admission. There was no family history of liver disease or haemochromatosis. He looked cachexic and unwell. There was hepatomegaly and coarse crepitations over both lung fields but no other clinical abnormality was present. Routine haematological and biochemical tests with chest radiography, barium meal, and intravenous cholangiography all gave normal results. Sputum cytology showed no malignant cells. Diagnostic laparotomy was carried out, and a granular, uniformly enlarged liver and spleen and cholelithiasis were found. Cholecystectomy, splenectomy, and liver biopsy were performed. Histology confirmed chronic cholecystitis and heavy iron deposition in the liver and spleen. Iron was present in the hepatocytes and Kupffer cells, and cirrhosis was absent. The patient made an uneventful recovery but was urgently re-admitted one month later with a Pancoast's tumour, subsequently confirmed at necropsy. After his abnormal histological findings at laparotomy, special investigations of the patient's iron metabolism were performed to determine the nature of his iron storage disease.

Serum collected before death was used in the study of iron binding proteins. Portions of liver and bronchial carcinoma were obtained within 12 hours of death, and kept at $-20 \mathrm{C}$ until studied. Polyacrylamide gel electrophoresis (PGE) of ${ }^{59} \mathrm{Fe}$-labelled patient's serum disclosed two ironbinding proteins, subsequently proved by immunoprecipitation to be ferritin and transferrin. A $70000 \mathrm{~g}$ supernatant of tumour homogenate was labelled with ${ }^{59} \mathrm{Fe}^{2}$ and on PGE was shown to contain ferritin with an isoelectric point of 499-5.0. Hepatic tissue similarly treated showed a different ferritin with an isoelectric point of $5 \cdot 6$, which is consistent with hepatic isoferritin. Serum showed serum iron $54 \mu \mathrm{mol} / 1(14-32 \mu \mathrm{mol} / \mathrm{l})(302 \mu \mathrm{g} / 100 \mathrm{ml}$ $(78-178 \mu \mathrm{g} / 100 \mathrm{ml}))$; total iron binding capacity $77 \mu \mathrm{mol} / 1(54-81 \mu \mathrm{mol} / 1)$ $(430 \mu \mathrm{g} / 100 \mathrm{ml}(302-452 \mu \mathrm{g} / 100 \mathrm{ml}))$; ferritin $3800 \mu \mathrm{g} / \mathrm{l}(360 \mu \mathrm{g} / \mathrm{l})$; and transferrin $1.8 \mathrm{~g} / 1(2-3 \mathrm{~g} / \mathrm{l})$. Tumour ferritin showed isoelectric point 4.95.0 and concentration of $93 \mu \mathrm{g} / \mathrm{g}$ of tumour protein. Hepatic ferritin showed an isoelectric point $5 \cdot 6$.

\section{Comment}

Necropsy studies confirmed that the iron overload in this patient was confined to the hepatic and splenic tissues. The localisation of iron in the Kupffer cells and hepatocytes is not typical of early primary haemochromatosis, and this prompted the search for another explanation for the patient's iron overload.

We have shown the presence of ferritin within the primary lung tumour. The isoelectric point differs from that of hepatic isoferritin, thereby distinguishing the two proteins and showing that the ferritin isolated from the tumour did not represent contamination but was in fact tumour derived. The high normal total iron binding capacity in 
the presence of a low transferrin level is explained by this abnormal tumour ferritin having the capacity to bind $30^{\circ}$ of the serum iron.

Excessive serum levels of ferritin may lead to an increased iron transfer to hepatic cells. ${ }^{3}$ In this patient the localisation of excessive iron is consistent with such an effect mediated by tumour ferritin. This in turn may have produced a stimulus to intestinal iron absorption. ${ }^{1}$

Although haemochromatosis will increase the risk of primary tumour development" it is an unlikely occurrence in this case. The atypical iron distribution limited to liver and spleen, lack of family history, and high iron binding capacity are against the diagnosis of primary haemochromatosis. Probably the bronchial carcinoma produced an abnormal ferritin that resulted in excessive iron absorption from the gastrointestinal tract and increased iron deposition in the liver and spleen.

We wish to thank Professor K E F Hobbs and Professor S Sherlock for their encouragement in the study of this patient.

Dr Batey is the recipient of a Postgraduate Medical Foundation scholarship from Sydney University, Australia.

${ }^{1}$ Arosio, P, Yokota, M, and Drysdale, J W, Cancer Research, 1976, 36, 1735.

2 Bates, G W, Schlabach, M R, fournal of Biological Chemistry, 1975, 250, 2177.

3 Worwood, M, Seminars in Haematology, 1977, 14, 3.

${ }^{4}$ Cavill, I, Worwood, M, and Jacobs, A, Nature, 1975, 256, 328.

${ }^{5}$ Bomford, A, and Williams, R, Quarterly fournal of Medicine, 1976, 45, 611.

(Accepted 29 fuly 1977)

Royal Free Hospital School of Medicine, London NW3 2QG

A K C LI, MA, FRCs, lecturer in surgery and senior surgical registrar

R G BATEY, FRACP, MRCP, research fellow, department of medicine

\section{Inhibition of stress-induced hyperprolactinaemia}

Evidence suggests that there is dual control of inhibition and stimulation of prolactin secretion. ${ }^{1}$ Inhibition appears to predominate under basal conditions and is probably mediated through dopamine. There is less certainty about the stimulatory pathway, but surges of prolactin secretion occur in some physiological and stressful states, such as sleep, nipple stimulation, general anaesthesia, and insulin-induced hypoglycaemia. This stimulatory pathway may include serotonin neurotransmission, since administration of L-tryptophan or 5hydroxytryptamine-precursors in central serotonin synthesisnoticeably increases the serum prolactin concentration, which is blunted by serotonin antagonists. ${ }^{2}$ Furthermore, the stress release of adrenocorticotrophic hormone by hypoglycaemia may be serotonin mediated. ${ }^{3}$ We therefore investigated whether serotonin neurotransmission mediated the release of prolactin in a young woman with stress-induced galactorrhoea.

\section{Case report}

A 19-year-old woman had had irregular menses before taking an oral contraceptive containing $0.1 \mathrm{mg}$ mestranol for six months. During this period her ankles were fractured in a road accident, although there was no head or chest trauma. A few hours after the accident she developed breast engorgement and spontaneous bilateral galactorrhoea, which persisted. Her menses did not return when the contraceptive was stopped, and she noticed continued minor breast discharge. Five months later she underwent general anaesthesia for an orthopaedic procedure and again noted breast engorgement, which persisted for three weeks. She was not taking medication and was euthyroid. Sellar tomography showed nothing abnormal and the basal serum prolactin concentration was normal.

The stress response was reproduced by inducing hypoglycaemia with insulin $0.1 \mathrm{U} / \mathrm{kg}$ intravenously so that prolactin was released, and then giving thyrotrophin-releasing hormone $250 \mu \mathrm{g}$ intravenously two hours later. This enabled the response of prolactin to a stimulus acting directly on the pituitary to be assessed. Because the stress pathway was thought to be serotoninergic she was given cyproheptadine $8 \mathrm{mg}$ by mouth seven-hourly for 21 hours, after which hypoglycaemia was induced and thyrotrophin-releasing hormone given as before (see figure).

The patient was treated with bromocriptine $2.5 \mathrm{mg}$ twice daily, and within four weeks she had her first menstrual period. The galactorrhoea disappeared, and the menses have continued regularly.

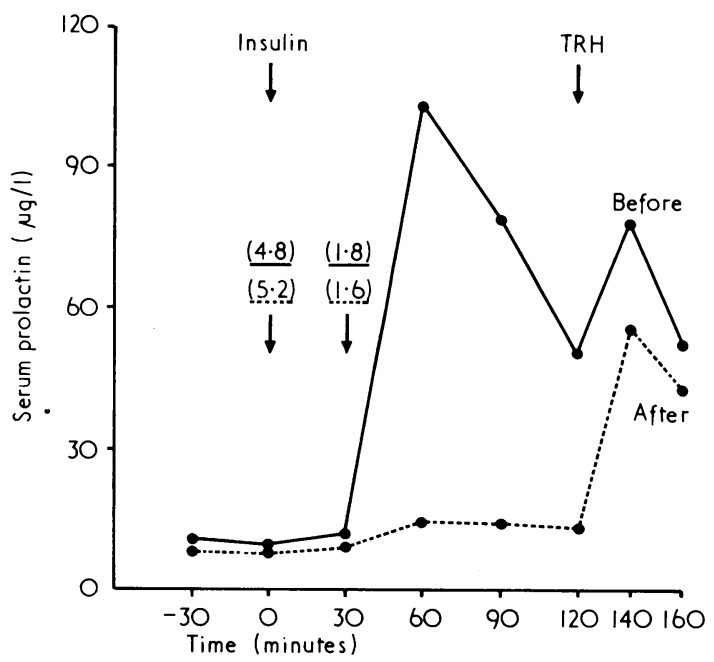

Response of serum prolactin to hypoglycaemia and thyrotrophin-releasing hormone (TRH) before and after treatment with cyproheptadine. Serum glucose concentrations (in $\mathrm{mmol} / \mathrm{l}$ ) are given in parentheses.

Conversion: SI to traditional units-serum glucose: $1 \mathrm{mmol} / 1=18 \mathrm{mg} / 100 \mathrm{ml}$

\section{Comment}

The patient twice developed stress-induced breast engorgement and also exhibited the syndrome of post-pill amenorrhoea with galactorrhoea. This syndrome may or may not be associated with an increased prolactin concentration. The oestrogen dose may have caused hyperplasia of the prolactin-secreting cells of the pituitary, ${ }^{\prime}$ which in turn may have caused the increased secretory response to stressful stimuli. Even though the basal serum prolactin concentration was consistently within the normal range she exhibited a dramatic rise in concentration in response to induced hypoglycaemia; this excessive stress response may have caused the post-trauma and post-anaesthesia breast engorgement. The inhibition by cyproheptadine of this hyperactive response to hypoglycaemia suggests that it may be mediated by serotonin neurotransmission, although cyproheptadine also has mild antihistaminic and antichlolinergic actions. Hypoglycaemia-induced cortisol secretion is inhibited by cyproheptadine, and this is clinically useful in treating Cushing's disease. ${ }^{3}$ There is an increase in hypothalamic serotonin content with insulin-induced hypoglycaemia, but, since both the hypothalamus and the pituitary contain serotonin, it is not yet known where the reaction that causes prolactin release occurs. Serotonin infused directly into the pituitary portal vessels failed to release prolactin, which suggests that the reaction takes place in the hypothalamus. ${ }^{3}$ Moreover, the fact that cyproheptadine did not interfere with the direct action of thyrotrophin-releasing hormone on prolactin release suggests that serotonin-mediated stress release of prolactin takes place at a functional level above the pituitary.

It is not known, however, whether the surge of prolactin in response to stress is mediated by a prolactin-releasing factor or by inhibition of the prolactin-inhibiting factor. Further studies are necessary to investigate the physiology of stress-induced prolactin release and to establish the exact role of serotonin neurotransmission.

Dr $\mathrm{H}$ Friesen kindly performed the prolactin assays.

Requests for reprints should be sent to Dr B Corenblum.

${ }^{1}$ Zacur, H A, et al, Lancer, 1976, 1, 410.

2 Kato, Y, et al, fournal of Clinical Endocrinology and Metabolism, 1974, 38, 695.

${ }^{3}$ Krieger, D T, et al, New England fournal of Medicine, 1975, 293, 893.

${ }^{4}$ Lloyd, H M, et al, International fournal of Cqncer, 1973, 11, 90.

5 Kamberi, I A, et al, Endocrinology, 1971, 88, 1288.

(Accepted 5 fuly 1977)

Faculty of Medicine, University of Calgary, Canada

B CORENBLUM, MD, $\operatorname{FRCP}(\mathrm{C})$, assistant professor

University Department of Internal Medicine, Foothills Hospital, Calgary, Canada

MICHAEL WHITAKER, MD, resident 